\title{
The Kerr nonlinearity of the beta-barium borate crystal
}

\author{
Bache, Morten; Guo, Hairun; Zhou, Binbin; Zeng, Xianglong
}

Published in:

CLEO/Europe 2013 - European Conference on Lasers and Electro-Optics

Link to article, DOI:

10.1109/cleoe-iqec.2013.6800966

Publication date:

2013

Link back to DTU Orbit

Citation (APA):

Bache, M., Guo, H., Zhou, B., \& Zeng, X. (2013). The Kerr nonlinearity of the beta-barium borate crystal. In CLEO/Europe 2013 - European Conference on Lasers and Electro-Optics IEEE. https://doi.org/10.1109/cleoeiqec.2013.6800966

\section{General rights}

Copyright and moral rights for the publications made accessible in the public portal are retained by the authors and/or other copyright owners and it is a condition of accessing publications that users recognise and abide by the legal requirements associated with these rights.

- Users may download and print one copy of any publication from the public portal for the purpose of private study or research.

- You may not further distribute the material or use it for any profit-making activity or commercial gain

- You may freely distribute the URL identifying the publication in the public portal

If you believe that this document breaches copyright please contact us providing details, and we will remove access to the work immediately and investigate your claim 


\section{The Kerr nonlinearity of the beta-barium borate crystal \\ Morten Bache ${ }^{1}$, Hairun Guo ${ }^{1}$, Binbin Zhou ${ }^{1}$, and Xianglong Zeng ${ }^{1,2}$}

${ }^{1}$ DTU Fotonik, Department of Photonics Engineering, Technical University of Denmark, DK-2800 Kgs. Lyngby, Denmark

${ }^{2}$ The Key Lab of Specialty Fiber Optics and Optical Access Network, Shanghai University, 200072 Shanghai, China A popular crystal for ultrafast cascading experiments is beta-barium-borate $\left(\beta-\mathrm{BaB}_{2} \mathrm{O}_{4}, \mathrm{BBO}\right)$. It has a decent quadratic nonlinear coefficient, and because the crystal is anisotropic it can be birefringence phase-matched for type I ( $O o \rightarrow e$ ) second-harmonic generation (SHG). For femtosecond experiments BBO is popular because of low dispersion and a high damage threshold. The main attractive property of ultrafast cascading is that the induced cascading nonlinearity $n_{2 \text {, casc }}^{I}$ can be negative, i.e. generate a self-defocusing Kerr-like nonlinearity. However, the material Kerr nonlinearity $n_{2, \text { Kerr }}^{I}$ is self-focusing and competes with the cascading nonlinearity. Therefore, precise knowledge of its strength is crucial. We perform an experiment measuring the main $c_{11}$ tensor component, and together with literature experimental data [1], we propose a $c_{11}$ value composed of 14 different data points.
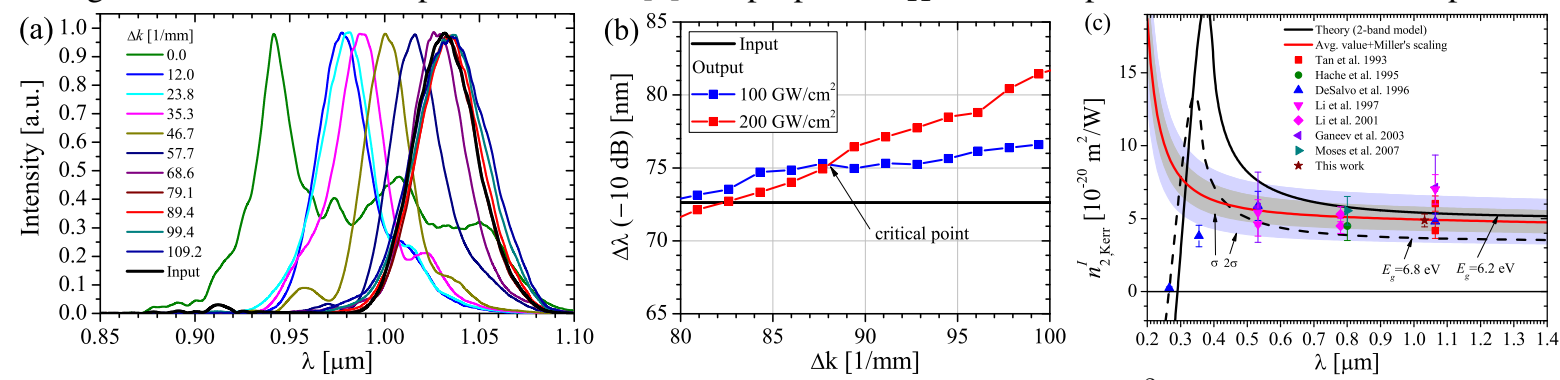

Figure 1. (a) Experimental spectra recorded with $50 \mathrm{fs@1030} \mathrm{nm} \mathrm{and} 200 \mathrm{GW} / \mathrm{cm}^{2}$ transform-limited pulses, (b) the spectral bandwidth@-10 dB vs. $\Delta k$. (c) Summary of the experimental data from the literature corresponding to the $c_{11}$ nonlinear susceptibility coefficient $\left(n_{2, \text { Kerr }}^{I}=3 c_{11} / 4 n_{1}^{2} \varepsilon_{0} c\right)$. The data are corrected by us for cascading contributions. The shaded areas " $\sigma$ " and " $2 \sigma$ " represent one and two standard deviations.

BBO is a negative uniaxial crystal in the point group $3 \mathrm{~m}$. When the pump is $o$-polarized, the nonlinear susceptibility component that accounts for the Kerr self-phase modulation (SPM) is $c_{11}=\chi_{X X X X}^{(3)}=\chi_{Y Y Y Y}^{(3)}$. We pumped a $25 \mathrm{~mm} \mathrm{BBO}$ cut for $o o \rightarrow e$ SHG with $50 \mathrm{fs} 1030 \mathrm{~nm}$ pulses from a commercial OPA. By tuning the phase mismatch away from zero cascading sets in as a Kerr-like SPM nonlinearity with the nonlinear index $n_{2, \text { casc }}^{I}=-2 \omega_{1} d_{\text {eff }}^{2} / c^{2} \varepsilon_{0} n_{1}^{2} n_{2} \Delta k$, where $d_{\text {eff }}$ is the effective quadratic nonlinearity, and $n_{1}$ and $n_{2}$ the FW and SH linear indices. Fig. 1(a) shows that for low $\Delta k$ the self-defocusing cascading dominates leading to strongly modulated and broadened spectra. At some critical point the cascading exactly cancels the material Kerr nonlinearity $n_{2, \text { casc }}^{I}+n_{2, \text { Kerr }}^{I}=0$. Such a zero SPM nonlinearity should leave the spectra invariant with intensity. We found this point by observing the $-10 \mathrm{~dB}$ bandwidth crossing of two different intensities, see Fig. 1(b). Then, by using the well-known quadratic nonlinearities for BBO we can calculate $n_{2, \mathrm{Kerr}}^{I}=-n_{2, \text { casc }}^{I}=4.9 \pm 0.4 \cdot 10^{-20} \mathrm{~m}^{2} / \mathrm{W}$, which corresponds to $c_{11}=4.7 \pm 0.4 \cdot 10^{-22} \mathrm{~m}^{2} / \mathrm{V}^{2}$. In the literature other experiments have measured the Kerr nonlinearity in BBO [1]. We have done a careful analysis of these to (a) clarify which tensor components were excited, (b) ensure consistent definitions of the Kerr nonlinearity and (c) correct for the deterministic contribution from cascaded SHG [2]. The summary is shown for the most important $c_{11}$ component in Fig. 1(c). The values agree surprisingly well with the two-band model, originally derived for wide-gap semiconductors. We confirmed that Miller's delta, calculated as $\Delta_{11}=c_{11} /\left(n_{1}^{2}\left(\lambda_{p}\right)-1\right)^{4}$, was nearly constant over all data at various pump wavelengths $\lambda_{p}$ (except the UV measurements below $400 \mathrm{~nm}$ that were not used). Therefore we could calculate a weighted mean over 14 data points as $\Delta_{11}=52.3 \pm 7.7 \cdot 10^{-24} \mathrm{~m}^{2} / \mathrm{V}^{2}$, which corresponds to $c_{11}=4.78 \cdot 10^{-22} \mathrm{~m}^{2} / \mathrm{V}^{2}$ and $n_{2, \text { Kerr }}^{I}=4.93 \cdot 10^{-20} \mathrm{~m}^{2} / \mathrm{W}$ at $1030 \mathrm{~nm}$. Our experiment agrees very well with this average. We finally analyze literature data [3] to obtain the 3 other tensor components $c_{10}, c_{16}$ and $c_{33}$ as well.

\section{References}

[1] H. Tan, G. P. Banfi, and A. Tomaselli, "Optical frequency mixing through cascaded second-order processes in beta-barium borate," Appl. Phys. Lett. 63, 2472-2474 (1993). F. Hache, A. Zéboulon, G. Gallot, and G. M. Gale, "Cascaded second-order effects in the femtosecond regime in $\beta$-barium borate: self-compression in a visible femtosecond optical parametric oscillator," Opt. Lett. 20, 15561558 (1995). R. DeSalvo, A. A. Said, D. Hagan, E. W. Van Stryland, and M. Sheik-Bahae, "Infrared to ultraviolet measurements of two-photon absorption and $\mathrm{n}_{2}$ in wide bandgap solids," IEEE J. Quantum Electron. 32, 1324-1333 (1996). H. Li, F. Zhou, X. Zhang, and W. Ji, "Bound electronic kerr effect and self-focusing induced damage in second-harmonic-generation crystals," Opt. Commun. 144, 75 - 81 (1997). H. P. Li, C. H. Kam, Y. L. Lam, and W. Ji, "Femtosecond Z-scan measurements of nonlinear refraction in nonlinear optical crystals," Opt. Mater. 15, 237-242 (2001). R. Ganeev, I. Kulagin, A. Ryasnyanskii, R. Tugushev, and T. Usmanov, "The nonlinear refractive indices and nonlinear third-order susceptibilities of quadratic crystals," Opt. Spectrosc. 94, 561-568 (2003). J. Moses, B. A. Malomed, and F. W. Wise, "Self-steepening of ultrashort optical pulses without self-phase modulation," Phys. Rev. A 76, 021802(R) (2007).

[2] M. Bache, H. Guo, B. Zhou, and X. Zeng, "The anisotropic Kerr nonlinear refractive index of the beta-barium borate $\left(\beta-\mathrm{BaB}_{2} \mathrm{O}_{4}\right)$ nonlinear crystal," submitted, arXiv: 1209.3158 .

[3] P. S. Banks, M. D. Feit, and M. D. Perry, "High-intensity third-harmonic generation,” J. Opt. Soc. Am. B 19, 102-118 (2002). M. SheikBahae and M. Ebrahimzadeh, "Measurements of nonlinear refraction in the second-order $\chi(2)$ materials $\mathrm{KTiOPO}_{4}, \mathrm{KNbO}_{3}, \beta$ - $\mathrm{BaB}_{2} \mathrm{O}_{4}$ and $\mathrm{LiB}_{3} \mathrm{O}_{5}$," Opt. Commun. 142, 294-298 (1997). 